\title{
Cronicar lo íntimo: las inflexiones autobiográficas y el lector confidente en las crónicas de Clarice Lispector
}

\author{
To chronicle the intimate: autobographical inflections and \\ confidant reader in Clarice Lispector's chronicles \\ Cronicar o íntimo: inflexões autobiográficas e leitor \\ confidente nas crônicas de Clarice Lispector
}

María Verónica Gutiérrez

\section{Resumen}

Las crónicas de Clarice Lispector, reunidas bajo el título Revelación de un mundo, publicadas en el Jornal do Brasil entre 1967 y 1973, aparecen como textos que, por su temática y recursos de escritura, cabalgan entre la crónica y las narrativas del yo, configurando un lugar de enunciación que se vuelve sobre la propia escritura para problematizar la cuestión genérica y la cuestión de los lectores. En este trabajo analizaré el cuerpo de crónicas de Lispector a partir de las categorías de "crónica personal", en la que podrían inscribirse las singulares incursiones de la escritora en la tradición del género, y de "intimismo espectacular" (Giordano), categoría que permite pensar la relación entre las crónicas de Lispector y los lectores.

Palabras-clave: crónica personal, narrativas del yo, género literario, intimismo espectacular, Clarice Lispector.

\begin{abstract}
Clarice Lispector's chronicles, collected under the title Discovering the World, and published in the Jornal do Brasil between 1967 and 1973, emerge as texts which, because of their topics and writing resources, vary from chronicles to self-narratives, shaping an enunciation that looks upon the author's own writing, in order to question the genre issue. In this paper, I will consider Lispector's chronicles on the basis of both "personal chronicle" -in which could be included the unique incursions of the author in the genre tradition- and "spectacular intimacy" categories, where the latter suggests the relationship between Lispector's chronicles and her readers.
\end{abstract}

Keywords: personal chronicle, self-narratives, literary genre, spectacular intimacy, Clarice Lispector.

\section{Resumo}

As crônicas de Clarice Lispector publicadas no Jornal do Brasil entre 1967 e 1973, e reunidas sob o título A descoberta do mundo, aparecem como textos que, por seu conteúdo e recursos de escrita, cavalgam entre a crônica e as narrativas do eu, configurando um lugar de enunciação que transforma a própria escrita para problematizar a questão genérica. Neste trabalho, analisarei o corpo de crônicas de Lispector a partir da categoria de "crônica pessoal", na qual poderiam inscrever-se as singulares incursões da escritora na tradição do gênero e de "intimismo espetacular" (Giordano) categoria que permite pensar sobre a relação entre as crônicas de Lispector e os leitores.

Palavras-chave: crônica pessoal, narrativas do eu, gênero literário, intimismo espetacular, Clarice Lispector.

Allí donde otros exponen su obra yo sólo pretendo mostrar mi espíritu. Vivir no es otra cosa que arder en preguntas.

Antonin Artaud

\footnotetext{
Doutoranda em Humanidades na Universidad Nacional de Tucumán, San Miguel de Tucumán, Tucumán, Argentina. (Dorcid.org/0000-0003-2991-9523. E-mail: vero.gutierrez29@gmail.com
} 


\section{Una crónica de la propia incertidumbre}

El archivo americano se abre con un relato de un viaje, el Diario de Cristóbal Colón sobre su primer viaje a las Indias, que es al mismo tiempo un cuaderno de bitácora y un informe a las autoridades, un escrito absolutamente híbrido difícil de alojar en la certeza de algún género. La literatura latinoamericana está atravesada desde sus orígenes por géneros híbridos como el testimonio, el relato de viajes, el diario íntimo, la entrevista, el ensayo. En ese espacio genérico liminar está, sin dudas, la crónica. Fruto innegable de los procesos de modernización que atravesó América Latina durante las dos últimas décadas del siglo XX y las primeras décadas del siglo XX, la crónica experimenta, hacia fines del siglo $\mathrm{XX}$, un resurgimiento como textualidad fuertemente ligada a "un acecho de lo real" (Bernabé, 2006, p. 10), aunque no necesariamente desde una estética realista (clásica). Ese resurgimiento se configura en un momento de crisis del discurso identitario latinoamericano y de cambio de paisaje. Las dictaduras en el continente, la violencia administrada por el terrorismo de Estado, el crecimiento de la pobreza y la marginalidad, la debacle neoliberal en los años ‘90, la reconfiguración de los espacios urbanos, fueron configurando el escenario en el que la crónica se constituyó como escritura que testimonia "la extrañeza radical que impone la experiencia de la vida en las urbes del capitalismo posindustrial" (Bernabé, 2006, p. 11) en el "campo expandido de la literatura actual" (Bernabé, 2015, p. 2): Pedro Lemebel en Chile, Carlos Monsiváis en México, Rubem Braga en Brasil, Edgardo Rodríguez Juliá en Puerto Rico, María Moreno o Cristian Alarcón en la Argentina, por citar solamente algunos nombres representativos.

Las nuevas crónicas se conectan con ese gran momento del género en América Latina que fue el de la crónica modernista hispanoamericana: una escritura urgente, signada por la velocidad que imponían los medios de comunicación masiva, vuelta sobre el fenómeno de la vida en las ciudades y preocupada por captar a los lectores ${ }^{1}$. Pensemos sobre todo en las crónicas que escribe Rubén Darío, aquellas publicadas en el diario La Nación de Buenos Aires. Señala Graciela Montaldo: "En sus crónicas Darío escribió sobre muchos temas que podían interesar a un lector moderno y educado: política, arte, literatura, vida cotidiana, actualidad, notas de color, chismes. Pero esa misma variedad también había empezado a interpelar a los nuevos públicos, los que recién accedían a la escritura y la lectura" (Montaldo, 2013, p. 14). Esa preocupación por los lectores a quienes se dirige la crónica, tan marcada en la escritura del Modernismo hispanoamericano, reaparecerá con fuerza en las crónicas de Lispector. Pero, como señala Elena Altuna, a diferencia de la crónica modernista, cuyo autor guardaba una distancia entre el sujeto escribiente y los acontecimientos relatados, de manera tal de introducir en el intersticio dejado entre él y lo contado un posicionamiento político o moral, en las crónicas contemporáneas, y entre ellas las de Clarice Lispector, el sujeto cronista "se posiciona en un lugar imaginario de pasaje y contacto entre los sectores que habitan la geografía urbana. Desde ese lugar de desplazamiento habla las lenguas de los grupos, sin ceder su perspectiva de cronista, para deshilvanar historias mínimas de mujeres y de hombres comunes" (Altuna, 2016, p. 117).

Esta contaminación, este inmiscuirse en el mundo de "lo real" hace que las nuevas crónicas se conviertan, a fin de cuentas, en "la autofiguración del que escribe frente a una realidad que se presenta básicamente como inenarrable" (Bernabé, 2006, p.11). Es decir, en los cronistas actuales se observa con recurrencia un acercamiento a la materia narrada como marca definitoria. Ese mecanismo de contaminación en el proceso de escritura hace que el cronista se convierta, muchas veces, en el objeto mismo de la crónica, en una subjetividad, como afirma Mónica Bernabé, que intenta poner en palabras, y en relato, la experiencia multiforme, caótica, heterogénea e, incluso, ininteligible, de vivir en las ciudades contemporáneas: "traman una subjetividad que prefiere imaginarse en medio de un cúmulo de flujos y corrientes que arrastran desechos y despojos de lo

\footnotetext{
${ }^{1}$ Cuando hablamos de Modernismo hispanoamericano, estamos hablando del vasto movimiento continental que supuso "una de las renovaciones más radicales de la escritura en español" (Montaldo, 2013, p. 11). Fuertemente ligado al proceso de modernización de América Latina, el Modernismo no puede comprenderse en su real caladura si no se lo vincula con ese proceso que se inicia hacia 1870 y se prolonga hasta la década de 1920. El escritor modernista exhibe una posición ambivalente frente a los cambios y la emergencia de nuevas sensibilidades: por un lado denuncia una sociedad que él vislumbra como excesivamente materialista (de ahí esa figura tan del Modernismo: el raro) y por otro trabaja por colocar sus textos, sobre todo las crónicas, en el circuito del mercado.
} 
real junto con motivos de sus propias vidas" (Bernabé, 2006, p.14). En la contemporaneidad, la crónica es la textualidad que registra la trama del vivir en las urbes del presente. En el mundo actual, caracterizado por una dificultad de tramitar el malestar por medio de lo simbólico -el síntoma moderno- y por optar por el pasaje al acto, la crónica aparece como una posibilidad cierta de relato allí donde prima no el orden simbólico sino el goce individual. No es extraño que el género en Latinoamérica registre diversas formas de violencia que modelan las últimas décadas en varias regiones del continente, pensemos en las crónicas de Alberto Salcedo Ramos sobre la situación de los campesinos colombianos flanqueados entre el ejército, los grupos paramilitares y la guerrilla, y los trabajos de Juan Villoro sobre el terror del narcotráfico mexicano.

Si la crónica ha sido siempre permeable a los elementos del discurso autobiográfico (géneros como la carta, el relato de viaje, el ensayo se hibridan frecuentemente con ella), estos han adquirido mayor fuerza en la crónica latinoamericana contemporánea, al punto de convertirse, como vimos, en uno de sus elementos recurrentes. Sin dudas, aquí hay que ubicar lo que algunos han dado en llamar "crónicas personales" (Wiener, 2012), aquellas en las que lo autobiográfico, lo privado y lo íntimo ocupan el lugar central de lo que se cuenta ${ }^{2}$. Un ejemplo claro es "Mi vida como hombre", del escritor argentino Alan Pauls, quien relata sus peripecias emocionales frente a un modelo de masculinidad en el que no encaja. Por supuesto que aquí lo personal no lo es estrictamente, y la crónica sobre sí mismo se expande, inevitablemente, hacia miradas sobre los discursos hegemónicos sobre los géneros, lo marginal, los límites y la distribución de las formas que asumen las relaciones sociales, y no rompe del todo con sus orígenes: presentarse como un registro de la realidad. Pueden situarse aquí también claramente, en esta zona difusa y fluctuante entre lo personal y lo social, muchas de las crónicas de Pedro Lemebel. Nueva vertiente de la crónica, ésta que se ubica en los márgenes de un género que es de por sí ya un espacio textual lábil e impreciso. El componente autobiográfico se manifiesta en procesos de subjetivación que delatan a un sujeto que en modo alguno es el "odioso yo pascaliano" (Hernández, 1997, p. 430) sino una subjetividad atravesada por las pérdidas (el exilio, la marginalidad, la indagación en las fronteras del propio cuerpo), los quiebres y las suturas provisorias, tan de las sociedades contemporáneas.

A descoberta do mundo (1984) reúne las crónicas que la escritora brasileña escribió durante siete años para el Jornal do Brasil, entre 1967 y 1973, y que pueden ubicarse en ese subgénero que son las crónicas personales. Luego fueron traducidas al español y editadas en dos volúmenes Revelación de un mundo (2004), que analizaremos aquí, y Descubrimientos (2010).

Lispector aborda en el cuerpo de crónicas de Revelación temáticas diversas, la infancia, la pobreza en Brasil, las clases sociales, el amor, la amistad, sus encuentros con Guimarães Rosa, Chico Buarque y Tom Jobim, pero generalmente articuladas desde sus experiencias vitales, a veces íntimas, por lo que las crónicas se convierten en una suerte de confesión a los lectores que, de esta manera, asisten al develamiento del mundo privado e interior de la mítica escritora.

Si pensamos en el discurso de lo privado como aquel que tiene que ver con la comunicación en la vida privada, con el lenguaje familiar y la transmisión de experiencias personales; y en el discurso de lo íntimo como aquel que asume el tono de la confesión de algún aspecto de la propia subjetividad, aspecto que, además, no se cuenta a nadie más que a quien lee o escucha esa revelación, habremos de concluir que las crónicas de Clarice Lispector asumen ambos registros discursivos y encabalgan con los géneros literarios que

\footnotetext{
${ }^{2}$ Señala la cronista peruana Gabriela Wiener refiriéndose a algunos de los tópicos que se discutieron en el "Encuentro de Nuevos Cronistas de Indias 2", realizado en México en el año 2012: “Ayer Julián Gorodischer señalaba ciertas vertientes novedosas de la crónica y sus puntos de encuentro con otras muchas manifestaciones de la cultura contemporánea. Comparto esas mismas preocupaciones. Comentaba él que en los medios masivos existen actualmente espacios para las crónicas personales, esas que se mueven en la frontera de lo público y lo privado. Hay demanda de este tipo de historias también en las revistas tradicionales de crónicas (Soho, Etiqueta Negra, Malpensante) que acogen crónicas testimoniales, experimentos de inmersión, ensayos personales o crónicas donde la memoria tiene un papel central. Y si hay demanda en los medios es porque los lectores también quieren leer estas historias. Martín Caparrós ha dicho reiteradas veces en este encuentro que cuando un cronista empieza a hablar más de sí mismo que de la historia, deja de ser un cronista. Discrepo. Creo que es peligroso seguir viendo a estas crónicas como elementos ajenos e infiltrados, cuando es un hecho que compartimos medios y lectores. Pasamos horas de horas tratando de delimitarnos, de estrechar los márgenes del género. ¿No sería más aburrida la crónica si expulsáramos del club a los que a veces les da por hablar 'de sí mismos'?” (Wiener, 2012).
} 
tradicionalmente alojaron estos discursos: los epistolarios, la autobiografía, el diario íntimo ${ }^{1}$. Las crónicas no escapan a la marca característica del resto de la obra de Lispector: la constante de una escritura sumamente personal. La reconstrucción de escenas de la infancia y las afirmaciones de la cronista tales como: "ser una inadaptada es mi fuerte" (Lispector, 2011, p. 31) o "tuve una angustiosa sensación de pérdida hace unos días" (p. 224), le dan a los escritos el tono íntimo de la confidencia, confidencias que los lectores del Jornal do Brasil leen con la avidez de quien escucha un secreto. Lispector, como lo hacen los géneros autobiográficos, construye "un espacio de seudointimidad que distorsiona y que revela la interioridad de los seres humanos" (Boria, 2009, p. 58), exagerando un gesto que ya está en la crónica, esto es, el simulacro discursivo de la experiencia (Bernabé, 2006, p. 11).

Abordaré, en este trabajo, aspectos de los textos de la Clarice Lispector cronista en los que su escritura se vuelve autorreflexiva y a partir de los cuales podré problematizar sobre la cuestión genérica -y sobre la figura del lector-, esto es, "la crónica personal" en tanto cuerpo textual profundamente híbrido que puede ubicarse, sin dudas, en el escenario de las literaturas del yo.

\section{Intimismo espectacular}

Clarice Lispector advierte, desde el principio, el carácter personal de sus crónicas. La presencia de sí misma en textos escritos para ser leídos por los miles de lectores del Jornal do Brasil la desconcierta. No puede llamar propiamente crónicas a las suyas porque le parecen excesivamente personales como para ser incluidas en la tradición genérica que tan bien cultivara Rubem Braga. Sobre esta cuestión de la propia escritura de crónicas Lispector vuelve una y otra vez, construyendo un yo/escribiente que no se siente a gusto con los moldes textuales pero que poco a poco irá instalándose en una comodidad provisoria.

Todavía me siento un poco perdida en mi nueva función con eso que no puede llamarse propiamente crónica. Y, además, de ser neófita en el asunto, también lo soy en materia de escribir para ganar dinero. Ya trabajé en prensa como profesional, sin firmar. Al firmar, sin embargo, me vuelvo automáticamente más personal. Y siento un poco como si estuviera vendiendo mi alma (Lispector, 2011, p. 16).

Nota: un día le telefoneé a Rubem Braga, el creador de la crónica, y le dije desesperada: "Rubem, no soy cronista, y lo que escribo se está volviendo excesivamente personal. ¿Qué hago?". Él dijo: "Es imposible, en la crónica, dejar de ser personal". Pero yo no quiero contar mi vida a nadie: mi vida es rica en experiencias y emociones vivas, pero no quiero publicar nunca una autobiografía. Pero aquí van mis recuerdos de un viaje por mar (p. 266).

La reflexión sobre el género textual es aquí, evidentemente, la reflexión sobre la propia escritura que deviene autobiográfica y termina situándose en los bordes de la crónica, pero es también la justificación, la legitimación, de lo que se escribe, siempre desde un espacio genérico lábil que caracteriza toda la obra de la brasileña, ante el público y la crítica. El yo de la escritura se mueve todo el tiempo entre la decisión de no escribir una autobiografía y el deseo de comunicación profunda consigo mismo y con el lector, otorgándole a las crónicas cierta tensión que se resuelve en textualidades complejas y contradictorias. La máquina de escribir solamente se detiene ante el pudor de contarlo todo: "Bien sé que tendré que detenerme, no a causa de la falta de palabras, sino porque estas cosas y sobre todo las que pensé y no escribí, no suelen publicarse en los diarios" (Lispector, 2011, p. 190). Ese ir y venir entre "la delicia y el tormento" que provoca dar a conocer el territorio de lo íntimo, marca que signa lo autobiográfico, se hace mucho más violento en estas crónicas en tanto siempre es inminente (todos los sábados, en el $J B$ ) la publicación. El lector inscripto en el texto funciona, entonces, como una suerte de confidente al que se le van confiando el pensamiento, los deseos y los fantasmas. Y si en primera instancia ese lector es el público anónimo del periódico brasileño, en algunas oportunidades adquiere un rostro y un nombre: las crónicas se escriben, en ocasiones, como respuestas a la carta que algún lector le ha escrito a la cronista, adquiriendo mayor fuerza la tonalidad de respuesta personal, privada, a un otro concreto, leída, sin embargo, por todo el mundo. A veces, las respuestas lo son a cartas que cuentan, también, experiencias privadas o 
que aconsejan a la cronista del Jornal, conformándose un simulacro de espacio de comunicación íntima, mixturado con un género como la carta.

Ésta viene de Cabo Frío, las iniciales son L. de A. La carta revela que quien la escribió recién empezó a leerme después de que comencé a escribir en el Jornal do Brasil, pues le llama la atención mi nombre, dice que bien podría ser Larissa [...] Y termina su carta diciendo: "No deje su columna con el pretexto de que quiere defender su intimidad. ¿Quién la reemplazaría?". Por ahora, L. de A., no estoy dejando la columna, sino aprendiendo una manera diferente de defender mi intimidad [...] Sin embargo, paradójicamente, y al lado del deseo de defender la propia intimidad, está el deseo intenso de confesarme en público y no con un padre. El deseo de decir finalmente lo que todos sabemos pero mantenemos en secreto como si estuviese prohibido decirles a los niños que Papá Noel no existe, aun sabiendo que saben que no existe. El personaje lector es un personaje curioso, extraño. Al mismo tiempo que completamente individual y con relaciones propias, está tan terriblemente ligado al escritor que en verdad él, el lector, es el escritor (Lispector, 2011, p. 57).

La figuración en el texto de un lector confidente es, sabemos, propia de los géneros autobiográficos. La fuerte presencia del "personaje lector", o del destinatario, es un rasgo de muchas crónicas pero es, sobre todo, un elemento característico de las narrativas del yo en tanto es a través de esa intensa presencia que se establece la ilusión comunicativa de la vida privada de quien cuenta ${ }^{3}$. Es decir, a pesar de las reticencias de Lispector por publicar escritos autobiográficos, sus crónicas se sitúan claramente en el conjunto diverso del género o de los géneros autobiográficos a instancias de compartir con éstos elementos fundamentales. El constante reflexionar sobre el género y la propia escritura hacen que lo que se ponga en escena sea, finalmente, un espacio de develamiento y enmascaramiento en el que quedan expuestos los mecanismos de construcción -selección, retaceo, exageración, silencios- de lo autobiográfico.

En el caso de las crónicas de Lispector, el simulacro de comunicación íntima alcanza su mayor grado de realización cuando los contornos absolutamente borrosos del lector anónimo se concretizan, por ejemplo, en el pedido que se le hace a un otro al que solamente la cronista conoce:

No es más que un pedido. Y estoy implorando. Estoy implorando para que usted no beba tanto [...] Pero tengo miedo de lo que me dicen de usted. Que usted está bebiendo tres veces más de lo que bebía. Imploro que usted no acorte la vida [...] Yo también estoy viviendo. En nombre del Dios en el que usted profundamente cree, monje como es, beba menos. No fue nada fácil para mí. Créame (Lispector, 2011, p. 54).

Los límites genéricos de la crónica tienden, en la escritura de Lispector, a hacerse aún más flexibles permitiendo incorporar como realidad cronicada todo el universo de los discursos privados e íntimos y de los géneros autobiográficos en un entramado textual en el que el yo se juega entre el pudor, y el silencio, y la revelación de la intimidad, erigiendo para sí la figura de un lector/confidente.

La escritura de la crónica puede pensarse aquí como lo que Alberto Giordano llama "intimismo espectacular" o "espectáculos de intimidad". Giordano utiliza esta idea para referirse a los apuntes - entre el ensayo y el diario íntimo - que llevó/publicó en Facebook entre los años 2014 y 2016, y que luego aparecieron bajo la forma del libro en El tiempo de la convalecencia (2017). Lo íntimo deviene espectáculo y reflexión sobre esa condición que adquiere la escritura y las cavilaciones del crítico-escritor ante la paradoja de hacer confidencias, incluso, a quienes no conoce. Los lectores de las crónicas de Lispector publicadas en el Jornal do Brasil, por otra parte,

\footnotetext{
${ }^{3}$ A partir de lo que Beatriz Sarlo llama el "giro subjetivo" y Alberto Giordano el "giro autobiográfico", el espacio de lo autobiográfico se ha ensanchado: "Si antes dicho espacio lo ocupaba sólo la autobiografía, éste ha acabado por incluir todo tipo de propuestas, desde las más convencionales - biografías, memorias o diarios al uso- hasta las más impredecibles - realities televisivos guionizados, documentales performáticos, novelas autoficcionales, etcétera-. Ello resulta especialmente relevante en el momento actual, cuando las diversas formas de la 'extimidad' (Tisseron, 2001, p. 52) y la 'espectacularización de la personalidad' (Sibilia, 2008, p. 133) están a la orden del día, y cuando el deseo de consumir vidas ajenas es más fuerte que nunca” (Casas, 2018).
} 
anticipan "el ansia por consumir chispazos de identidad ajena" (Sibilia, 2008, p. 221), tan de las sociedades contemporáneas- "sociedades espectacularizadas" las llama Paula Sibilia-, cuyo escenario privilegiado es Internet -lugar en el que se pondrán en escena las "confesiones reveladas por un yo que insiste en mostrarse siempre real" (Sibilia, 2008, p. 222).

Cronicarse a sí misma podría aparecer como una contradicción pues, desde sus inicios, el gesto de la crónica es la de contar lo que se encontraría fuera del sujeto, sin embargo, como ya señalé, el género crónica también contiene desde sus inicios elementos autobiográficos. Las crónicas actuales no ocultan esos elementos y esa particular forma del género que puede llamarse "crónica personal" los exagera hasta convertirlos en el centro textual provocando un desplazamiento, esto es, una objetivización del sujeto que se convierte en materia relatable para sí mismo y para otros. Características de la carta y la autobiografía son absorbidas por las crónicas personales de Clarice Lispector, otros cronistas incorporarán otras formas del amplio espectro de las literaturas del yo, como las del diario íntimo, o las del relato de viajes, pero lo interesante es que el resultado es siempre un cuerpo textual profundamente rico, que implica y pone en juego los espacios de lo público, lo privado y lo íntimo, contando la interioridad del sujeto en el marco de un género literario-periodístico que supone la lectura masiva de lo que se escribe.

\section{La escritura como mecanismo de autoconocimiento}

Si la escritura de la crónica resulta conflictiva para un yo cronista que se encuentra traccionado por un doble deseo, el de no convertir el texto en una revelación de sí, desplegando mecanismos de defensa de la intimidad (no escribir sobre lo que nadie escribiría en un periódico, por ejemplo) y, a la vez, el impulso de contarlo todo, esa escritura constituye también un mecanismo de autoconocimiento y de conocimiento del mundo. La idea de revelación que recorre estas crónicas es, al mismo tiempo, revelación-descubrimiento del mundo, revelaciónconocimiento de sí y revelación de esos misterios (mundo y yo) a los lectores. La escritura es el medio, el instrumento, el artilugio de los que se vale la escritora para la develación: "Me habría gustado ser una luchadora [...] Terminé siendo una persona que busca lo que siente profundamente y usa la palabra que lo exprese" (Lispector, 2011, p. 130).

El estilo en algunas de las crónicas es el del lenguaje desencadenado remedando el fluir de la conciencia, los recorridos del pensamiento, el salto gratuito e inconexo de una idea a otra; en una misma crónica, se pasa de la conversación con un taxista de Río de Janeiro a un recuerdo de la infancia en Recife, para saltar luego a una reflexión sobre las relaciones amorosas y la educación sentimental. Podría decirse que la escritura asume la forma de una búsqueda interior que consiste en encontrar las palabras adecuadas para expresar algo del orden del pensamiento o de los sentimientos.

Mis intuiciones se vuelven más claras con el esfuerzo de expresarlas con palabras [...] porque escribir es una manera de no mentir el sentimiento (la transfiguración involuntaria de la imaginación es tan sólo un modo de llegar); por otro lado, escribo por la incapacidad de entender, si no es a través del proceso de escribir. Si adopto un aire hermético, es porque no sólo lo principal es no mentir el sentimiento sino porque tengo la incapacidad de expresarlo de un modo claro sin mentirlo (Lispector, 2011, p. 180).

La puesta en palabras puede ser de estados interiores tan profundos como los de la angustia, la nostalgia o la cólera, "ya no sé escribir, perdí el don" (Lispector, 2011, p. 92), "amanecí con cólera" (p. 24), y lo único capaz de detener la pulsión de la escritura es, como vimos, el pudor o la necesidad de que el lector, pues a fin de cuentas Lispector piensa cuando escribe en el lector de un periódico, no se encuentre con el hermetismo y una oscuridad infranqueables.

Como en una autobiografía, Clarice Lispector dedica varias crónicas a la rememoración de la infancia, una infancia que se postula como la primera instancia de configuración del yo y, por consiguiente, como instancia primera y elemental para ese proceso de autoconocimiento y revelación que arremete con la escritura. La Lispector-niña re-construida se encuentra atravesada por el vacío y la extrañeza que le provoca la presencia de una madre terriblemente enferma y por la culpa de no haber podido curar a esa madre enferma con su nacimiento. Ella, 
niña- extraña en un mundo incomprensible, había sido engendrada con la esperanza de que su nacimiento curara a la madre, tal como decía la sabiduría popular.

Sin embargo, fui preparada para ser dada a luz de un modo muy bonito. Mi madre estaba ya enferma, y, por una superstición muy difundida, se creía que tener un hijo curaba a una mujer de su enfermedad [...] Entonces fui deliberadamente creada: con amor y esperanza. Sólo que no curé a mi madre. Y siento hasta el día de hoy esta carga de culpa: me hicieron para una misión determinada y fallé [...] Sé que mis padres me perdonaron por haber nacido en vano y haberlos traicionado en la gran esperanza. Pero yo, yo no me perdono. Querría que simplemente se hubiera cumplido un milagro: nacer y curar a mi madre. Entonces, sí: ya habría pertenecido a mi padre y a mi madre. Yo no podía confiar a nadie esta especie de soledad de no pertenecer (Lispector, 2011, p. 91).

Esa marca infantil, en el gran relato de la vida cronicada de Lispector (la novela familiar), aparece en la escritura como el origen de lo que vendrá después, el sentimiento de no pertenencia y un gusto por la soledad que la escritora cultiva durante años, apareciendo muy pocas veces en público. Reticente ante la mirada del otro, desarrolla cierta timidez e inseguridad descriptas en las crónicas: "Hay personas que tienen vergüenza de vivir: son los tímidos, entre los cuales me incluyo" (Lispector, 2011, p. 315). Infancia, culpa, timidez, son algunos de los materiales con los que la cronista va erigiendo la historia familiar y la historia del sujeto, y el proceso de contar lo ocurrido es, como en toda escritura autobiográfica, un artilugio de reconstrucción del yo desde el presente y en función del momento presente, con ingredientes de autoconocimiento y autojustificación.

El yo de las crónicas publicadas en el $J B$ desconfía de la escritura fácil y rápida, "estoy escribiendo con mucha facilidad, y con mucha fluidez, hay que desconfiar de eso" (Lispector, 2011, p. 289), porque concibe la escritura como un esfuerzo, un trabajo arduo que hace explícito algo que, antes de la escritura, le era difuso. El tópico, presente en la literatura universal, de la lucha con el lenguaje para hacerle decir lo que, tal vez, con palabras nunca se alcance a decir, reaparece en estas crónicas de Lispector, en este caso, bajo la forma de un decirse a sí mismo, de un yo cronicado descubierto ante los lectores del Jornal do Brasil, que sábado a sábado asisten la revelación de un mundo.

\section{Bibliografía}

ALTUNA, Elena (2016). Pedro Lemebel: crónicas de la orfandad urbana. En: Elena Altuna y Betina Campuzano (Eds.). Vertientes de la contemporaneidad. Géneros híbridos y nuevas subjetividades en la literatura latinoamericana. Salta: EUNSa. pp. 115-124.

BORIA, Adriana (2009). El discurso amoroso. Tensiones en torno a la condición femenina. Córdoba: Comunicarte.

BERNABÉ, Mónica (2006). Prólogo. CRISTOFF, María Sonia (Comp.). Idea crónica. Literatura de no ficción iberoamericana. Buenos Aires: Beatriz Viterbo.

BERNABÉ, Mónica (2015). La hibridez no basta. Lectura mundi, Buenos Aires, p. 1-4, nov.-dic. En línea: http://www.unsam.edu.ar/lecturamundi/sitio/wp-content/uploads/2016/08/5-La-cronica-encuesti\%C3\%B3n.pdf

GIORDANO, Alberto (2006). Una posibilidad de vida. Escrituras íntimas. Rosario: Beatriz Viterbo.

GIORDANO, Alberto (2011). Vida y obra. Otra vuelta al giro autobiográfico. Rosario: Beatriz Viterbo.

GIORDANO, Alberto (2017). El tiempo de la convalecencia. Rosario: Iván Rosado.

HERNÁNDEZ, Francisco Javier (1997). Escritura autobiográfica y destinatario. Thélème. Revista Complutense de Estudios Franceses, Madrid, n. 11, p. 427-438.

LISPECTOR, Clarice (2010). Descubrimientos. Traducción de Claudia Solans. Buenos Aires: Adriana Hidalgo. 
LISPECTOR, Clarice (2011). Revelación de un mundo. Traducción de Amalia Sato. Buenos Aires: Adriana Hidalgo (Primera edición 2004).

MONTALDO, Graciela (2013). Guía Rubén Darío. In: DARÍO, Rubén. Viajes de un cosmopolita extremo. Selección y prólogo de Graciela Montaldo. Buenos Aires: Fondo de Cultura Económica. p. 11-51.

SARLO, Beatriz (2005). Tiempo pasado. Cultura de la memoria y giro subjetivo. Una discusión. Buenos Aires: Siglo XXI.

SIBILIA, Paula (2008). La intimidad como espectáculo. Buenos Aires: Fondo de Cultura Económica.

WIENER, Gabriela (2012). Mis crónicas ejemplares. Revista Ñ, 16 oct. En línea: https:/ / bit.ly/2krcMMg. 